\title{
Metodologia CAJEDUS para o Desenvolvimento de Jogos de Apoio à Educação Infantil Bilíngue de Crianças Surdas: Um Estudo de Caso Junto a Desenvolvedores
}

\author{
Ludmilla Fernandes Oliveira Galvão $^{1}$, Laura Sánchez García ${ }^{1}$, Tanya Amara Felipe ${ }^{2}$ \\ ${ }^{1}$ Programa de Pós-Graduação em Informática - Universidade Federal do Paraná (UFPR) \\ Curitiba - PR - Brasil. \\ ${ }^{2}$ Instituto Nacional de Educação de Surdos (INES) \\ Rio de Janeiro - RJ - Brasil. Endereço \\ \{ludmillagalvaol, sg.laura, tanyafelipe\}@gmail.com
}

\begin{abstract}
The Deaf community needs computational tools to support Bilingual Education, with Libras as the preferred language and Portuguese as a second language, since the early stages of childhood. One way to assist the teaching and learning process is the use of educational games. The problem is that many are not accessible, and so, disregarding the objectives of Bilingual Education. From this gap the methodology CAJEDUS (Creation of Educational Games for Deaf Children) was built. That said, a case study was conducted for the design of educational games for Deaf children aged 4 and 5 by developers with little or no contact with Bilingual Early Childhood Education and Deaf culture.
\end{abstract}

Resumo. A comunidade Surda necessita de ferramentas computacionais para o apoio da Educação Bilíngue, com Libras como língua preferencial e Português como segunda língua, desde as fases iniciais da infância. Uma forma de auxiliar o processo de ensino e aprendizagem é a utilização de jogos educativos. O problema é que muitos não são acessíveis e, em o sendo, desconsideram os objetivos da Educação Bilíngue. A partir dessa lacuna, foi construída a metodologia CAJEDUS (CriAção de Jogos para a EDUcação de crianças Surdas). Assim sendo, foi conduzido um estudo de caso para a concepção de jogos educativos para crianças Surdas de 4 e 5 anos por desenvolvedores com pouco ou nenhum contato com a Educação Infantil Bilíngue e cultura Surda.

\section{Introdução}

Um dos principais desafios na educação básica brasileira é como formular estratégias para assegurar que todas as crianças recebam um ensino de base de qualidade. Em particular, as crianças Surdas têm dificuldades em se adaptar ao ensino regular, o qual visa o ensino do Português como primeira língua (L1), sendo que sua comunicação é majoritariamente gestual-visual. Visando essa dificuldade, instituições como o INES (Instituto Nacional de Educação de Surdos) trabalham com a proposta metodológica de uma Educação Bilíngue [Felipe 2006], na qual a Libras (Língua Brasileira de Sinais) é utilizada/ensinada como sua primeira língua (L1) e o Português como a segunda língua (L2).

Nesse contexto, os jogos educativos podem ser utilizados como recursos didáticos para a aquisição de conhecimento por crianças Surdas, levando em consideração a "importância do letramento para o desenvolvimento de habilidades cognitivas e sociais" 
[Aristizábal et al. 2017]. Porém, ainda que existam jogos para auxiliar o letramento e a aquisição de conhecimento por crianças Surdas [Chebka e Essalmi 2015], muitos ainda dependem somente de textos em mecânicas e interfaces, criando ainda mais barreiras e resistência na aprendizagem das crianças Surdas. Outro problema, central a esta pesquisa, é a não inclusão de educadores ou de documentos pedagógicos adequados no processo de construção de jogos educativos, a fim de que o conteúdo apresentado no jogo seja pertinente aos objetivos de aprendizado das crianças.

Levando em consideração esse cenário, foi desenvolvida a CAJEDUS, uma metodologia multidisciplinar para a concepção de jogos educativos para crianças Surdas de 4 e 5 anos por desenvolvedores com pouco ou nenhum contato com a Educação Infantil Bilíngue e cultura Surda [Galvão 2020]. Além da criação de jogos educativos acessíveis a partir dos objetivos de aprendizagem da Educação Infantil Bilíngue, a metodologia pretende apoiar os desenvolvedores no "processo de conscientização e sensibilização em relação ao público infantil Surdo" [Galvão 2020]. O presente artigo discutirá as lições aprendidas com relação ao estudo de caso com desenvolvedores de jogos utilizando a metodologia CAJEDUS.

\section{Metodologia CAJEDUS}

A metodologia CAJEDUS foi construída a fim de oferecer o insumo necessário para que desenvolvedores possam construir jogos educativos para crianças Surdas de 4 e 5 anos. Esses jogos educativos deverão estar alinhados com objetivos de aprendizagem da Educação Infantil [Brasil e CNE 2010, MEC 2017] e da Educação Infantil Bilíngue [Cruz et al. 2015], levando em conta aspectos de acessibilidade, de sensibilização em relação aos direitos humanos e estímulo ao aprendizado e imersão das crianças Surdas.

Dessa forma, a CAJEDUS era constituída de 4 instrumentos: 1. Diretrizes Gerais (DG), que apresentavam aspectos éticos e de acessibilidade para crianças Surdas, relacionados a questões de aprendizagem e implementação, baseando-se nas orientações do Ministério da Educação (MEC) [Brasil e CNE 2010, MEC 2017]; 2. Diretrizes de Campo de Experiência e Aprendizado (DCEA), que complementavam as DG e visavam orientar os desenvolvedores em relação aos campos de experiência e aprendizado [MEC 2017] que poderiam ser exploradas pelo jogo; 3. Direcionamento Educacional (DE), que apresentava conteúdos e objetivos para crianças Surdas de 4 e 5 anos baseandose em Cruz et al. (2015), providenciando o contexto da Educação Bilíngue; e 4. Game Design Document (GDD), construído para que os desenvolvedores pudessem formalizar os aspectos do jogo decididos pela equipe, como conteúdo a ser abordado pelo jogo, mecânicas, interface, história, etc.

Assim sendo, a metodologia se dava pela leitura e estudo dos três primeiros instrumentos (DG, DCEA e DE) na ordem e forma preferencial dos desenvolvedores, seguido pela confecção do GDD com o conhecimento obtido por essa leitura. E, por último, os desenvolvedores criariam um protótipo de jogo educativo de baixa ou média fidelidade. A Figura 1 apresenta o funcionamento da metodologia CAJEDUS.

\section{Estudo de Caso e Discussões}

A fim de avaliar a metodologia CAJEDUS com relação ao seu potencial de criação de jogos por desenvolvedores, foi realizado um estudo de caso. O objetivo era encontrar 


\section{Metodologia CAJEDUS}

$\begin{array}{lll}\text { Leitura das DG } \quad \text { Leitura das DCEA } \quad \text { Leitura das DE } & \begin{array}{c}\text { Confecção do } \\ \text { GDD }\end{array}\end{array} \begin{gathered}\text { Confecção do } \\ \text { Protótipo de Jogo }\end{gathered}$

Figura 1. Passos da metodologia CAJEDUS.

benefícios e problemas na CAJEDUS e como ocorriam. Foram escolhidos 4 participantes dentro do público-alvo da CAJEDUS, ou seja, especialistas em desenvolvimento de jogos com pouca ou nenhuma experiência com crianças Surdas.

A atividade proposta no estudo de caso consistiu na criação de um protótipo de jogo educativo RPG (Role Play Game) eletrônico para crianças Surdas de 4 e 5 anos. O gênero RPG eletrônico foi escolhido pela sua afinidade com os objetivos de aprendizagem da Educação Infantil Bilíngue. O cenário dado aos participantes foi construído baseado em uma demanda dos professores do INES, para auxiliar no ensino da cultura indígena às crianças Surdas.

O experimento consistiu na leitura dos materiais disponibilizados da CAJEDUS e a realização de um brainstorming de ideias do jogo pelos participantes. A partir das ideias consolidadas, os participantes confeccionaram o GDD e o protótipo. Em seguida, os participantes preencheram um questionário pós estudo baseado no TAM (Technology Acceptance Model) com o objetivo de capturar as impressões dos participantes quanto à utilidade, à facilidade e à intenção de uso futuro da CAJEDUS. E por último, eles participaram de uma entrevista em grupo, cujo objetivo era obter respostas em relação às suas impressões da metodologia como um grupo.

O jogo especificado pelos participantes era um RPG eletrônico para celular, na qual uma criança Surda (protagonista personalizável) iria visitar uma tribo conhecida como Urubus Kaapor para conhecer mais sobre sua cultura. O jogador deveria aprender habilidades cotidianas dos indígenas, coletar itens e desviar de perigos na floresta, a fim de preencher um diário para mostrar aos colegas da escola. A Figura 2 apresenta fotos do experimento juntamente com o protótipo construído.

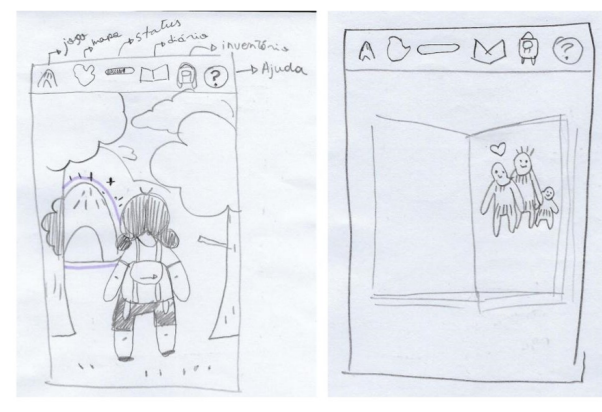

Participantes do estudo
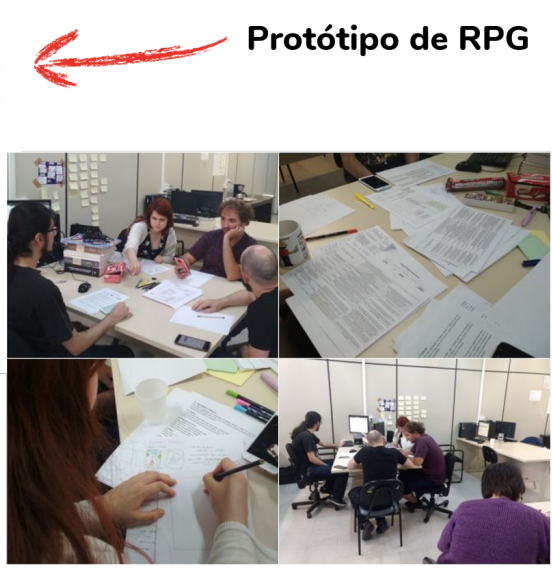

Figura 2. Protótipo produzido e fotos dos participantes. 
A partir da leitura e análise do jogo, percebeu-se que faltou detalhamento em alguns pontos, apesar do material produzido cobrir o esperado de um GDD e protótipo funcionais. Adicionalmente, foram feitas uma análise quantitativa das questões múltipla escolha do questionário e uma análise qualitativa dos dados textuais do estudo, as questões discursivas do questionário e o áudio transcrito da entrevista.

Em relação à análise quantitativa, percebeu-se que os participantes tiveram problemas para compreender a metodologia, assim como exigiu esforço mental significativo. Esse problema derivou-se da extensão e complexidade da versão da CAJEDUS avaliada. Apesar disso, a metodologia cumpriu com seu objetivo de auxiliar os desenvolvedores de jogos com pouco ou nenhum contato com a cultura ou educação Surda a construírem jogos educativos para tal público. Além disso, a CAJEDUS auxiliou os desenvolvedores a aprenderem sobre a cultura Surda e a Educação Infantil Bilíngue, fazendo-os criar interesse em utilizar a metodologia futuramente.

Em relação à análise qualitativa, a CAJEDUS foi classificada como útil, abrangente (poderia ser utilizada para outros gêneros de jogos) e passível de aplicação outros contextos (crianças com outras especificidades educacionais). Apesar disso, a metodologia foi considerada confusa e cansativa, pela falta de um roteiro claro. Os participantes sugeriram apresentar a metodologia de uma forma mais dinâmica, como, por exemplo, por um jogo de cartas.

Pela entrevista, houveram discussões sobre a importância de construir jogos de outro gênero sem ser os mais comumente utilizados, como puzzle e aventura, já que isso propõe outro papel de atuação para criança. Os participantes também afirmaram que a metodologia permitiu a compreensão das reais necessidades das crianças Surdas, quebrando esteriótipos que os mesmos tinham. Adicionalmente, para os participantes, a CAJEDUS mostrou-se uma metodologia que leva a visão dos desenvolvedores em consideração, oferecendo algo mais consistente que "o jogo tem que ser bonito e acessível". Os participantes ainda afirmaram que a CAJEDUS não deve se limitar à bolha dos especialistas em desenvolvimento de jogos, mas também dar voz às crianças Surdas, a fim de oferecer protagonismo à criança na criação de tecnologias educacionais.

Portanto, foi possível constatar que os participantes acharam a CAJEDUS útil para criar jogos para crianças Surdas, auxiliando na compreensão do gênero RPG eletrônico e dos conteúdos da Educação Infantil Bilíngue. O feedback e as sugestões obtidas, como criar um roteiro de instruções da metodologia, simplificar e melhorar a visualização dos instrumentos da CAJEDUS, ofereceram a oportunidade de a pesquisadora refinar a metodologia ${ }^{1}$. A Figura 3 sumariza os resultados obtidos no estudo de caso.

\section{Conclusão}

Este trabalho teve por objetivo apresentar as lições aprendidas no estudo de caso realizado para avaliar a metodologia de criação de jogos educativos CAJEDUS. Constatou-se que apesar de alguns problemas em relação à sua visualização, que foram corrigidos, a CAJEDUS se provou útil para seu objetivo. Cabe destacar que esta é uma metodologia multidisciplinar, cuja construção envolveu conhecimentos da Educação Infantil, da Educação Infantil Bilíngue e de Design de Jogos. Após ter construído este conhecimento,

\footnotetext{
${ }^{1}$ Link para acesso: https://bit. $1_{\mathrm{y}} / 2 \mathrm{Cj} \mathrm{b} 4 \mathrm{Fd}$
} 

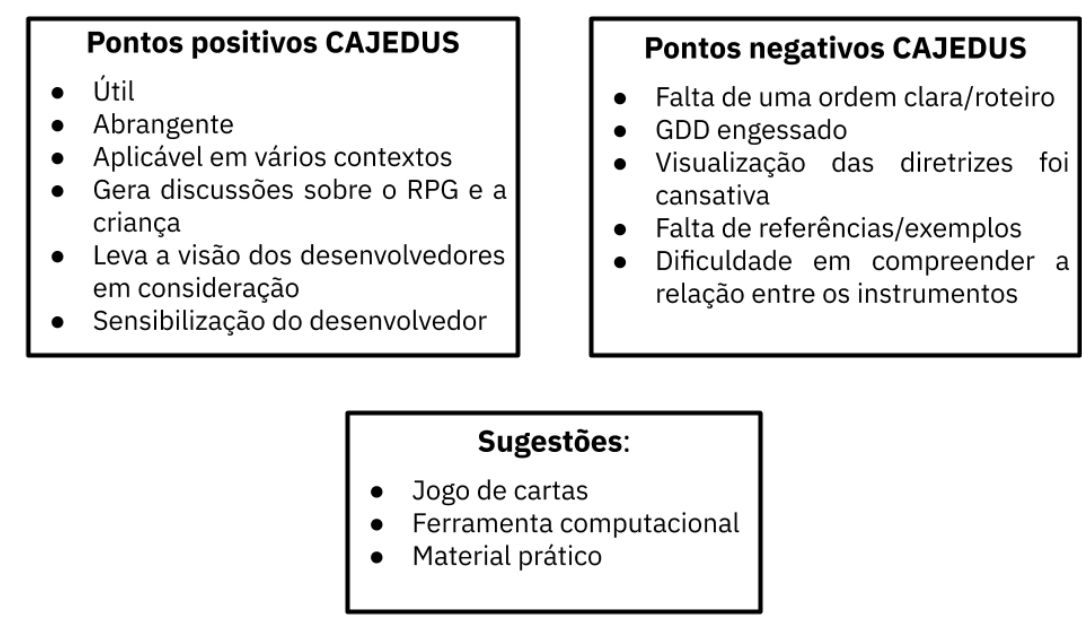

Figura 3. Sumarização dos dados obtidos com o estudo de caso.

é possível afirmar que este é o aspecto diferencial em relação a outros trabalhos disponíveis e, também a principal contribuição científica do presente trabalho.

Além disso, a metodologia CAJEDUS provou-se ser um meio eficaz de conscientização, permitindo que os desenvolvedores carreguem as lições aprendidas para projetos futuros. Uma possibilidade viável para a CAJEDUS é sua adaptação para crianças de outros contextos educacionais, garantindo dessa forma suas característica essenciais. Como trabalho futuro, a metodologia será estendida e adaptada de forma a permitir um processo participativo de construção dos jogos envolvendo também os perfis do professor da Educação Bilíngue e da própria criança Surda.

\section{Referências}

Aristizábal, L. F., Cano, S., e Collazos, C. (2017). Using storytelling to support the education of deaf children: A systematic literature review. In International Conference of Design, User Experience, and Usability, pages 371-382. Springer.

Brasil, M. e CNE, C. (2010). Diretrizes curriculares nacionais para a educação infantil. Resolução CEB-CNE, (01).

Chebka, R. e Essalmi, F. (2015). A crosswords game for deaf. In 2015 5th International Conference on Information \& Communication Technology and Accessibility (ICTA), pages 1-6. IEEE.

Cruz, A. M., Miranda, J., Rossi, H., Maia, M. C., Mojon, Q. H., e Felipe, T. A. (2015). Plano anual para educação infantil bilíngue para crianças surdas - 4 e 5 anos. Curso de Especialização Educação Bilíngue. INES, Rio de Janeiro - RJ.

Felipe, T. A. (2006). Política públicas para inserção da libras na educação de surdos. Revista Informativo-Científico Espaço. INES - Rio de Janeiro, (25/26):33-47.

Galvão, L. F. O. (2020). Cajedus: Uma metodologia para concepção de jogos educativos para crianças surdas baseados em objetivos de aprendizagem da educação infantil. Master's thesis, Universidade Federal do Paraná.

MEC, M. d. E. (2017). Base nacional comum curricular: educação é a base. MEC Brasília, DF. https://www.mec.gov.br/. 